Original Research Paper

\title{
Bacteria as Quantum Clocks
}

\author{
Atanas Todorov Atanasov \\ Department of Physics and Biophysics, Medical Faculty, Trakia University, Stara Zagora, Bulgaria
}

Email: atanastod@abv.bg

\begin{abstract}
In this study we have investigated the biological application of Wigner's inequalities for smallest quantum clock. We have shown that the mass, size and doubling time of bacteria satisfied the Wigner's inequalities for quantum clock. Data on 17 bacteria with mass $1 \times 10^{-17}-1 \times 10^{-15} \mathrm{~kg}$, size $0.3-50 \mu \mathrm{m}$ and doubling time $1 \times 10^{3}-1 \times 10^{5}$ seconds confirmed the hypothesis of Pešić that possibly the living bacteria appear to be the smallest quantum clocks in the Nature.
\end{abstract}

Keywords: Time, Quantum Clock, Wigner Inequality, Bacteria

\section{Introduction}

The application of quantum mechanics to biological systems is of great interest for theoretical and experimental areas of biological sciences. One spatial case of application of quantum mechanics is to examine the living cells and bio-molecules as 'quantum clocks'. The 'quantum clock' is a concept developed by Wigner and Salecker $(1957$; 1972) for the non-living physical systems. Later this concept was applied for black hole (Barrow, 1996), living cells (Pešić, 1993) and cellular enzymes (Goel, 2008). The Pešić model of bacteria as 'quantum clock' is supported on inequalities of Wigner (Salecker and Wigner, 1958) for a smallest clock with maximum size ' $L$ ' and mass ' $M$ '. Based on quantum mechanical considerations these scientists found that the longest Time $(T)$ for a clock that can remain accurate is presented by 'the first inequality':

$$
T<M \lambda^{2} / \hbar
$$

where, $\hbar=1.05 \times 10^{-34} \mathrm{~J} \cdot \mathrm{s}$ is the Planck's constant and $\lambda$ is the spread in position of the clock during time $T$. The smallest time interval that a clock can accurately measure $(\tau)$ is presented 'by the second inequality':

$$
\tau>(T / \tau)\left(\hbar / M c^{2}\right)
$$

where, ' $c$ ' is the speed of the light and $T / \tau$ is the number of tick of the clock, during the time.

Pešić (1993) first considered the possibility of extending the concept of the clock to biological systems. He observed that in the case of mycoplasmas with cell mass $M=8 \times 10^{-17}(\mathrm{~kg})$ and reproduction (doubling) time $T=50(\mathrm{~min})$ the calculated $\lambda$ is greater than $0.07 \mu \mathrm{m}$. The calculated value of $\lambda$ is near to the experimentally measured diameter of the mycoplasma of $0.3 \mu \mathrm{m}$. The conclusion of Pešić was that the cell parameters of mycoplasmas are consistent with inequality (1) and the mycoplasmas actually behave as Wigner clocks with accuracy of $10^{-16} \mathrm{~s}$. Against this concept there is contradiction (Brualla, 2013). Brualla concluded that the current experimental evidence does not support the validity of Wigner inequalities in a biological context. Thus, this problem remains open for resolution. In this work we support the biological application of Wigner's inequalities by wide range of experimental data on Prokaryotes (bacteria).

\section{Working Hypothesis}

During growth and dividing of cells by binary the cellular parameters (mass, size and form) of the mother and the daughter cells differ slightly, because of the genetic program in the cells. Genetic program determines the cellular mass and size of the daughter cell, but does not determine the doubling time for which the mother's cell grows and divided by binary. The duration of the doubling time depends on many external parameters (temperature, food sources, $\mathrm{pH}$, ion composition of environment, type of power source) and other factors, which are not under genetic control of the mother's cell. In this sense the doubling time of the cells appears to be non-defined and relatively random parameter that could be changed in given defined time interval. This time interval must be around the quantum limit of longest doubling time for cellular division. This is possibly as living cells work principally as quantum clocks. This means that during 
bacterial growth the cell size changes continuously similarly to the spread ' $\lambda$ ' in position of the quantum clock. The calculated by Pešić (1993) maximum spread $\lambda=0.07(\mu \mathrm{m})$ is very near to the volume to surface ratio of mycoplasma, about $\sim 0.05 \mu \mathrm{m}$. For example, for spherical mycoplasma with diameter D $0.3(\mu \mathrm{m})$ the volume to surface ratio is equals to $\mathrm{D} / 6$. Similarly to that in our calculations as more representative length we take the volume to surface ratio of bacterial cells (thus, we considered that maximum spread $\lambda$ is equals to volume to surface ratio of bacteria). The other argument in favor of the volume to surface ratio as representative length is the relatively constant value of volume to surface ratio during cell growth and dividing by binary (Atanasov, 2012). Because of that, we calculate the bacterial time-characteristics ( $T$ and $\tau$ ) as function of bacterial Mass $(M)$, size $(V / S)$ and Planck constant $(\hbar)$, accordingly to Wigner equations.

\section{The Aim of the Study}

- $\quad$ The aim of the study is to calculate the smallest $(\tau)$ and the longest $(T)$ times, accordingly to Wigner equations, using data for bacterial mass, size and doubling time

- To identify the real bacterial time-parameters, that correspond to this calculated smallest $(\tau)$ and longest (T) Time

- To show that the real bacterial parameters satisfy the Wigner equations for quantum clock

\section{Methods and Data}

We calculated the longest time interval ' $T$ ' for a quantum clock, accordingly to Equation 1, taken the equality:

$$
T=M \lambda^{2} / \hbar
$$

The calculated values of $T$ were compared with the doubling time $T_{d t}$ of bacterial cells, taken from the reported sources.

We calculated the smallest time interval ' $\tau$ ' for a clock accordingly Equation 2, using the data for the longest time $T$, bacterial mass $M$, the speed of light $c=$ $3 \times 10^{8} \mathrm{~m} / \mathrm{s}$ and the Planck constant $\hbar=1.05 \times 10^{-34} \mathrm{~J} \cdot \mathrm{s}$ :

$$
\tau=(T / \tau)\left(\hbar / M c^{2}\right)
$$

For this purpose, the formula (4) can be presented as the equation:

$$
\tau^{2}=T \hbar / M c^{2}
$$

On Table 1 are given the data for 18 bacteria with small, middle and big body mass. The doubling time, size and shape of bacteria are given too. The data for bacterial mass, size and doubling time were taken from scientific publications and sources (Furness and de Maggio, 1972; Waites and Talkington, 2004; Boatman and Kenny, 1970; Razin and Cosenza, 1966; Stemler et al., 1987; Gusev and Mineeva, 1985; Schlegel, 1985; Salser et al., 1968; Gouin et al., 1999; Finster et al., 1992; La Riviere and Schmidt, 2006; Bock, 1976; Starr and Schmidt, 1981; Higgins et al., 1973).

The bacterial volume to surface ratio $(V / S=\lambda)$ was calculated using the data for the size and shape of bacteria, accordingly to the standard formulas, used for algal cells (Hillebrand et al., 1999; Sun and Liu, 2003). On Fig. 1 are given the main bacterial shapes, the geometric parameters and formulas for calculation of volume and surface of bacterial cells. The shape of bacteria was present as sphere, short cylinder, long cylinder and disk. The small bacteria have predominantly spherical shape until the longest bacteria have the form of long cylinder.

If we replace $\lambda$ with $V / S$ ratio, the Equation 3 takes the form:

$$
T=M(V / S)^{2} / \hbar
$$

The smallest time interval was calculated by the equation:

$\tau^{2}=T \hbar / M c^{2}$

where, $T$ is calculated by the Equation 6 . Thus, the Equation 6 and 7 represent the working formulas.
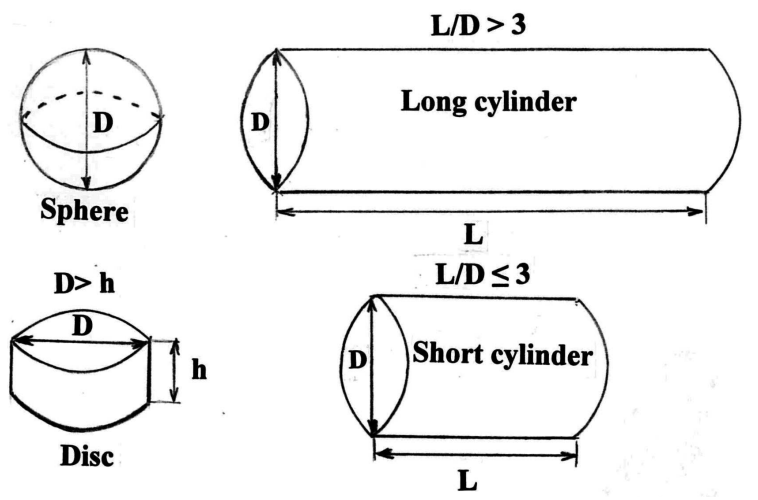

Fig. 1. Geometric shape and equations for Volume (V) and Surface area (S) of bacteria. Legend: Sphere: $V=$ $\pi D^{3} / 6, S=\pi D^{2}$; short cylinder: $V=\pi D^{2} L / 4, \quad S=$ $\pi D(D / 2+L)$, where $D \approx L$ or $L / D \leq 3.0$; long cylinder: $V=\pi D^{2} L / 4, S=\pi D L$, where $D \square \square L$ or $L / D>3.0$; disk: $V=\pi D^{2} h / 4, S=\pi D(D / 2+h)$, where $D>h$ 


\section{Results}

On Table 1 the bacterial mass varied about $10^{3}$ folds from $1 \times 10^{-17} \mathrm{~kg}$ in Mycoplasma mycoides to $7 \times 10^{-15} \mathrm{~kg}$ in Spirohaeta lutea. The size varied about $2 \times 10^{3}$ folds from smallest Mycoplasma with diameter $0.3 \mu \mathrm{m}$ to longest Spirohaeta with length $50 \mu \mathrm{m}$. The doubling time varied about $3.6 \times 10^{2}$ folds from $20 \mathrm{~min}$ in Escherichia coli to $30 \mathrm{~h}$ in Thiobacillus thioparus.

On Table 2 are given the calculated smallest and longest time intervals of the bacteria, accordingly to Equations 3-5. The smallest time interval ' $\tau$ ' gives the accuracy of bacterial clocks, whereas the longest time ' $\mathrm{T}$ ' gives the running time of bacterial clock.

On Fig. 2 are presented the data for $T(s), T_{d t}(s)$ and $\tau$ $(s)$ as function of bacterial body mass $\mathrm{M}(\mathrm{kg})$.

On Fig. 2 the calculated values of bacterial clock accuracy ' $~ \tau$ ' lies below the line of ATP time $\left(t_{A T P}=\right.$ $\left.1.1 \times 10^{-14}-1.1 \times 10^{-13} s\right)$. This time corresponds to the energy of one ATP molecule, calculated by the timeenergy uncertainty principle:

$t_{A T P} \times \varepsilon_{A T P} \geq h$

where, $\varepsilon_{A T P}=6.0 \times 10^{-21}-6.0 \times 10^{-20}(\mathrm{~J})$ is the free energy of one ATP molecule (Minkov, 1991) and $h=$ $6.6262 \times 10^{-34}(\mathrm{~J} \cdot \mathrm{s})$ is the Planck constant. The mean accuracy of the bacterial clock $\tau_{\text {mean }}=6.65 \times 10^{-16}(\mathrm{~s})$ lies near to the time of $\tau_{A T P}=1.1 \times 10^{-16}(\mathrm{~s})$, corresponding to the energy of $E_{A T P}=6.0 \times 10^{-18} \mathrm{~J}$, calculated by timeenergy uncertainty principle:

$\tau_{A T P} \times E_{A T P} \geq h$

In this case the equality $\tau_{A T P} \approx \tau_{\text {mean }}$ is valid (with error less than one order of magnitude), where any given value of $\tau$ satisfied the second Wigner's inequality in the form of $\tau>\tau_{A T P}$.

On Fig. 2 the calculated mean value of the longest (running) time $T_{\text {mean }}=6.88 \times 10^{4}(\mathrm{~s})$ is near to the mean value of the bacterial doubling time $T_{d t \text { mean }}=2.82 \times 10^{4}$ (s). The minimum and maximum values of the doubling time $\left(T_{d t \text { min }}, T_{d t_{\max }}\right)$ are given by two dashed lines. The more of the calculated values for $\mathrm{T}$ falls between $T_{d t \text { min }}$ and $T_{d t \max }$ lines. Between the mean value of doubling time $T_{d t \text { mean }}$ and the mean value of the calculated running time $T_{\text {mean }}$ almost equality $\left(T_{d t \text { mean }} \approx T_{\text {mean }}\right)$ is valid, where any given value of $T$ satisfied first Wigner's inequality in the form of $T<T_{d t} \max$. In additional, between the calculated longest time $T$ and the experimental values of $T_{d t}$, a relatively good correlation (with correlation coefficient $\mathrm{R}=0.47$ ) exists.

Table 1. Data for mass $(M)$, size $(D, h, L)$, shape and doubling time $(T d t)$ of bacteria

\begin{tabular}{|c|c|c|c|c|}
\hline Bacteria $\left(\mathrm{t}^{\circ} \mathrm{C}\right)$ & Mass M(kg) & $\begin{array}{l}\text { Size }(\mu \mathrm{m}) \\
\text { D-diameter } \\
\text { h-width } \\
\text { L-length }\end{array}$ & Shape & Doubling time $T d t(\min )$ \\
\hline 1. Mycoplasma mycoides $\left(37^{\circ}\right)$ & $1.55 \times 10^{-17}$ & $\mathrm{D}=0.3$ & $\mathrm{sph}$ & 60 \\
\hline 2. Mycoplasma pneumoniae $\left(37^{\circ}\right)$ & $6.91 \times 10^{-17}$ & $\mathrm{D} \times \mathrm{L}=0.2 \times 2.0$ & $1 \mathrm{cyl}$ & 73 \\
\hline 3. Mycoplasma felis $\left(37^{\circ}\right)$ & $4.32 \times 10^{-17}$ & $\mathrm{D} \times \mathrm{h}=0.5 \times 0.2$ & disc & $60-87$ \\
\hline 4. Mycoplasma hominis $\left(35^{\circ}\right)$ & $3.88 \times 10^{-17}$ & $\mathrm{D}=0.40$ & sph & 60 \\
\hline 5. Mycoplasma arthritidis $\left(37^{\circ}\right)$ & $1.55 \times 10^{-17}$ & $\mathrm{D}=0.30$ & $\mathrm{sph}$ & $20-120$ \\
\hline 6. Ureaplasma urealyticum $\left(37^{\circ}\right)$ & $2.75 \times 10^{-17}$ & $\mathrm{D}=0.22$ & sph & 74 \\
\hline 7. Bdelovibrio bacteriovorus $\left(35^{\circ}\right)$ & $7.77 \times 10^{-17}$ & $\mathrm{D} \times \mathrm{L}=0.3 \times 1.0$ & sh cyl & $20-300$ \\
\hline 8. Walbachia melophagi $\left(35^{\circ}\right)$ & $4.62 \times 10^{-17}$ & $\mathrm{D} \times \mathrm{L}=0.3 \times 0.6$ & sh cyl & $25.2-300$ \\
\hline 9. (a) Staphylococcus aureus $\left(37^{\circ}\right)$ & $1.24 \times 10^{-16}$ & $\mathrm{D}=0.6$ & $\mathrm{sph}$ & $23-120$ \\
\hline (b) Staphylococcus aureus $\left(37^{\circ}\right)$ & $5.76 \times 10^{-16}$ & $\mathrm{D}=1.0$ & $\mathrm{sph}$ & 309 \\
\hline 10. (a) Bacillus subtilis $\left(37^{\circ}\right)$ & $2.16 \times 10^{-16}$ & $\mathrm{D} \times \mathrm{L}=0.5 \times 1.0$ & sh cyl & 225 \\
\hline (b) Bacillus subtilis $\left(37^{\circ}\right)$ & $3.45 \times 10^{-16}$ & $\mathrm{D} \times \mathrm{L}=1.0 \times 4.0$ & $1 \mathrm{cyl}$ & 225 \\
\hline 11. Escherichia coli $\left(37^{\circ}\right)$ & $1.38 \times 10^{-16}$ & $\mathrm{D} \times \mathrm{L}=0.4 \times 1.0$ & sh cyl & $20-150$ \\
\hline 12. Ricketsia prowazeki $\left(37^{\circ}\right)$ & $6.22 \times 10^{-17}$ & $\mathrm{D} \times \mathrm{L}=0.3 \times 0.8$ & sh cyl & 480 \\
\hline 13. Ricketsia conorii $\left(37^{\circ}\right)$ & $6.22 \times 10^{-16}$ & $\mathrm{D} \times \mathrm{L}=0.6 \times 2.0$ & 1 cyl & 480 \\
\hline 14.Thiobacillus thioparus $\left(30^{\circ}\right)$ & $6.47 \times 10^{16}$ & $\mathrm{D} \times \mathrm{L}=0.5 \times 3.0$ & sh cyl & 2000 \\
\hline 15. (a) Spirochaeta lutea $\left(35^{\circ}\right)$ & $4.32 \times 10^{-16}$ & $\mathrm{D} \times \mathrm{L}=0.1 \times 50$ & 1 cyl & 240 \\
\hline (b) Spirohaeta lutea $\left(35^{\circ}\right)$ & $7.0 \times 10^{-15}$ & $\mathrm{D} \times \mathrm{L}=0.2 \times 200$ & $1 \mathrm{cyl}$ & 240 \\
\hline 16. (a) Nitrobacter agilis $\left(35^{\circ}\right)$ & $1.3 \times 10^{-16}$ & $\mathrm{D} \times \mathrm{L}=0.5 \times 0.6$ & sh cyl & 420 \\
\hline (b) Nitrobacter agilis $\left(35^{\circ}\right)$ & $5.53 \times 10^{-16}$ & $\mathrm{D} \times \mathrm{L}=0.8 \times 1.0$ & sh cyl & 420 \\
\hline 17. Lactobacillus acidophilus $\left(37^{\circ}\right)$ & $9.1 \times 10^{-17}$ & $\mathrm{D} \times \mathrm{L}=0.5 \times 1.5$ & sh cyl & 45 \\
\hline
\end{tabular}

* sph-sphere; sh cyl - short cylinder; 1 cyl - long cylinder 
Table 2. Calculated data for volume to surface ratio $(\lambda)$, longest time interval $(T)$ and smallest time interval $(\tau)$ of bacteria. Data for the doubling time $\left(T_{d t}\right)$ are taken from Table 1 and recalculated in seconds

\begin{tabular}{lllll}
\hline Bacteria $\left(\mathrm{t}{ }^{\circ} \mathrm{C}\right)$ & $\lambda(\mu \mathrm{m})$ & $\mathrm{T}(\mathrm{s})$ & $\mathrm{Tdt}(\mathrm{s})$ & $\tau(\mathrm{s})$ \\
\hline 1. Mycoplasma mycoides & 0.0500 & $3.690 \times 10^{2}$ & $3.60 \times 10^{3}$ & $1.67 \times 10^{-16}$ \\
2. Mycoplasma pneumonia & 0.0500 & $1.645 \times 10^{3}$ & $4.38 \times 10^{3}$ & $1.67 \times 10^{-17}$ \\
3. Mycoplasma felis & 0.0555 & $1.267 \times 10^{3}$ & $5.22 \times 10^{3}$ & $1.84 \times 10^{-16}$ \\
4. Mycoplasma hominis & 0.0670 & $5.910 \times 10^{4}$ & $3.60 \times 10^{3}$ & $1.33 \times 10^{-15}$ \\
5. Mycoplasma arthritidis & 0.0500 & $3.690 \times 10^{2}$ & $7.20 \times 10^{3}$ & $1.67 \times 10^{-16}$ \\
6. Ureaplasma urealyticum & 0.0370 & $3.580 \times 10^{2}$ & $4.44 \times 10^{4}$ & $1.23 \times 10^{-16}$ \\
7. Bdelovibrio bacteriovorus & 0.7500 & $4.16 \times 10^{5}$ & $1.80 \times 10^{4}$ & $6.6 \times 10^{-17}$ \\
8. Walbachia melophagi & 0.0594 & $1.55 \times 10^{3}$ & $1.8 \times 10^{4}$ & $2.0 \times 10^{-16}$ \\
9. (a) Staphylococcus aureus & 0.1000 & $1.18 \times 10^{4}$ & $7.2 \times 10^{3}$ & $3.33 \times 10^{-16}$ \\
(b) Staphylococcus aureus & 0.1700 & $1.58 \times 10^{5}$ & $1.84 \times 10^{4}$ & $5.65 \times 10^{-16}$ \\
10. (a) Bacillus subtilis & 0.1000 & $2.06 \times 10^{4}$ & $1.35 \times 10^{4}$ & $3.16 \times 10^{-16}$ \\
(b) Bacillus subtilis & 0.2500 & $1.87 \times 10^{5}$ & $1.35 \times 10^{4}$ & $7.94 \times 10^{-16}$ \\
11. Escherichia coli & 0.0830 & $9.05 \times 10^{3}$ & $9.0 \times 10^{3}$ & $2.76 \times 10^{-16}$ \\
12. Ricketsia prowazeki & 0.1300 & $1.0 \times 10^{5}$ & $2.88 \times 10^{4}$ & $1.40 \times 10^{-15}$ \\
13. Ricketsia conorii & 0.0630 & $2.35 \times 10^{3}$ & $2.88 \times 10^{4}$ & $1.40 \times 10^{-15}$ \\
14. Thiobacillus thioparus & 0.1250 & $9.6 \times 10^{4}$ & $1.2 \times 10^{5}$ & $4.16 \times 10^{-16}$ \\
15. (a) Spirochaeta lutea & 0.0250 & $2.57 \times 10^{3}$ & $1.44 \times 10^{4}$ & $0.83 \times 10^{-16}$ \\
(b) Spirohaeta lutea & 0.0500 & $1.70 \times 10^{5}$ & $1.44 \times 10^{4}$ & $1.67 \times 10^{-16}$ \\
16. (a) Nitrobacter agilis & 0.0880 & $9.587 \times 10^{3}$ & $2.52 \times 10^{4}$ & $2.93 \times 10^{-16}$ \\
(b) Nitrobacter agilis & 0.1430 & $1.07 \times 10^{5}$ & $2.52 \times 10^{4}$ & $1.40 \times \times 10^{-15}$ \\
17. Lactobacillus acidophilus & 0.0325 & $9.154 \times 10^{4}$ & $2.77 \times 10^{3}$ & $3.42 \times 10^{-15}$
\end{tabular}

$\mathbf{T}, \mathbf{T}_{\mathbf{d t}}, \tau, \tau_{\mathrm{ATP}}(\mathbf{s})$

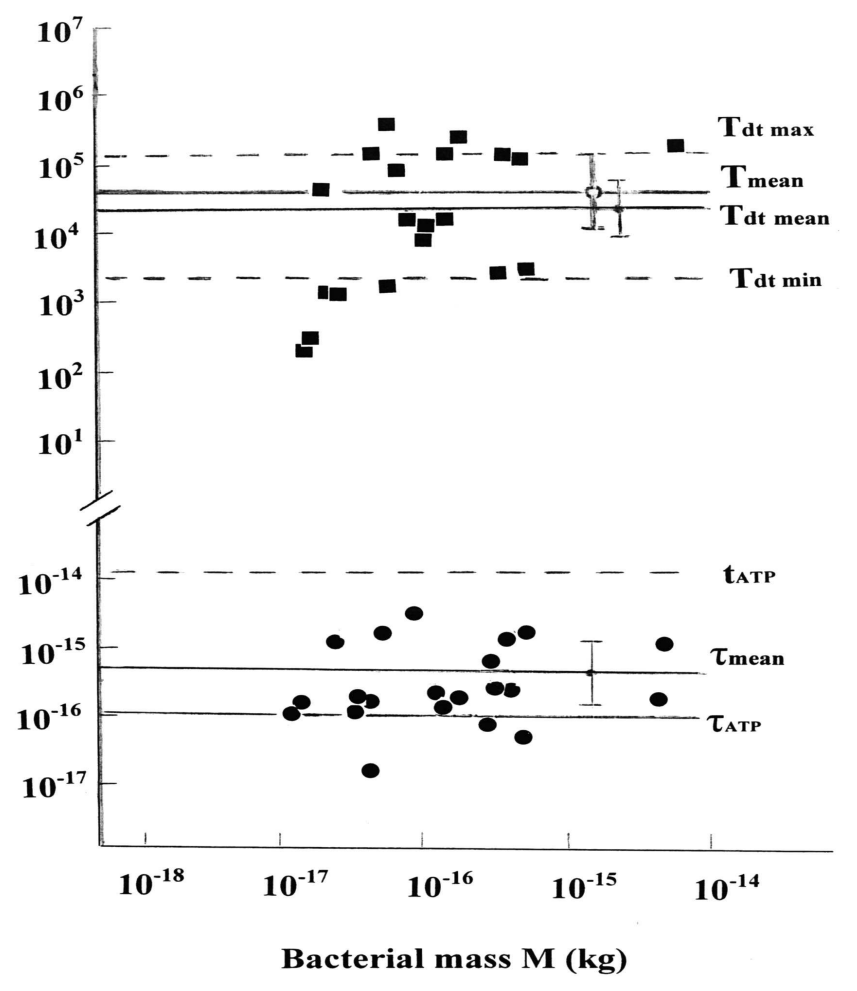

Fig. 2. Comparison between the running time $(T)$, accuracy $(\tau)$, bacterial doubling time $\left(T_{d t}\right)$ and ATP times $\left(t_{A T P}\right.$ and $\left.\tau_{A T P}\right)$ of bacterial clock. The times $T_{\text {mean }}=6.88 \times 10^{4} \mathrm{~s}, T_{d t \text { mean }}=2.82 \times 10^{4} \mathrm{~s}, \tau_{\text {mean }}=6.65 \times 10^{-16} \mathrm{~s}$ and $\tau_{A T P}=1.1 \times 10^{-16} \mathrm{~s}$ are marked with horizontal continuous line. The time of $t_{A T P}=1.1 \times 10^{-14} \mathrm{~s}$ is marked by dashed line. Standard deviations $( \pm \mathrm{SD})$ for $T_{\text {mean }}$ $\left( \pm 9.89 \times 10^{4} \mathrm{~s}\right)$, for $T_{d t \text { mean }}\left( \pm 4.7 \times 10^{4} \mathrm{~s}\right)$, and for $\tau_{\text {mean }}\left( \pm 7.2 \times 10^{-16} \mathrm{~s}\right)$ are shown 


\section{Model of Bacteria as Quantum Clock}

The operation of the bacterial cell as a quantum clock can be illustrated with the model represented on Fig. 3 . The clock starts to work with the starting growth of the bacteria-mothers. In the end of the growth of the mother cell (after $T_{d t}$ ) appears the bacteria-daughter. There is an understanding that the enzyme machines only received ATP energy for time $t_{A T P}$ or $\tau_{A T P}$, but the utilization of the full ATP energy occurs during the time $\left(t_{E}\right)$ of the enzyme reaction (Mohseni et al. 2014; Davies, 2004). In the model we take the mean enzyme reaction-time to be $t_{E}$ $\approx 1.0 \times 10^{-5}(\mathrm{~s})$ (Metzler, 1977) and one enzyme reaction-time to cause one clockwise movement. For mean total metabolic energy per one doubling time (TME $\left.\approx 1.0 \times 10^{-10} \mathrm{~J}\right)$ and mean basal metabolic rate per bacteria $\left(P_{\text {met }} \approx\right.$ $1.0 \times 10^{-13} \mathrm{~J} / \mathrm{s}$ ), the bacterial cell consumes $\mathrm{E}_{A T P}=10^{-18}(\mathrm{~J})$ for one enzyme reaction-time $\left(10^{-5} \mathrm{~s}\right)$ (Atanasov, 2005). The energy of $10^{-18} \mathrm{~J}$ corresponds to energy of $10^{2}-10^{3}$ ATP molecules i.e., $\mathrm{E}_{A T P}=\left(10^{2}-10^{3}\right) \times \varepsilon_{A T P}$, where $\varepsilon_{A T P}$ is the energy of a single ATP molecule. The time corresponding to the mean value of $\mathrm{E}_{A T P}=6 \times 10^{-18}(\mathrm{~J})$, calculated by the time-energy inequality $\left(\mathrm{E}_{A T P} \times \tau_{A T P} \geq \mathrm{h}\right)$, is $\tau_{A T P}=1.1 \times 10^{-16}$ (s). This time is very close to the mean calculated accuracy of the bacterial clocks $\tau_{\text {mean }}=6.65 \times 10^{-16}(\mathrm{~s})$. Thus, in the model the accuracy of bacterial clock is defined from the total ATP energy $\left(\mathrm{E}_{A T P}\right)$ exhausted from whole bacterial cell for one enzyme reaction-time. The same total ATP energy $\left(\mathrm{E}_{A T P}\right)$ causes one clockwise movement. The ratio between the total metabolic energy $T M E \approx 10^{-10}(\mathrm{~J})$ and the energy of $\mathrm{E}_{A T P}=10^{-18}(\mathrm{~J})$ gives the number of all $\mathrm{E}_{A T P}$ quanta: $T M E / E_{A T P}=N=10^{8}$. Product between the number of these quanta $(\mathrm{N})$ and mean enzyme-time $\left(\mathrm{t}_{\mathrm{E}}\right)$ gives the clock running time (T), nearly equals to the doubling time $T \approx T_{d t}$ $=N \times t_{E}$ of given cell- Fig.3.

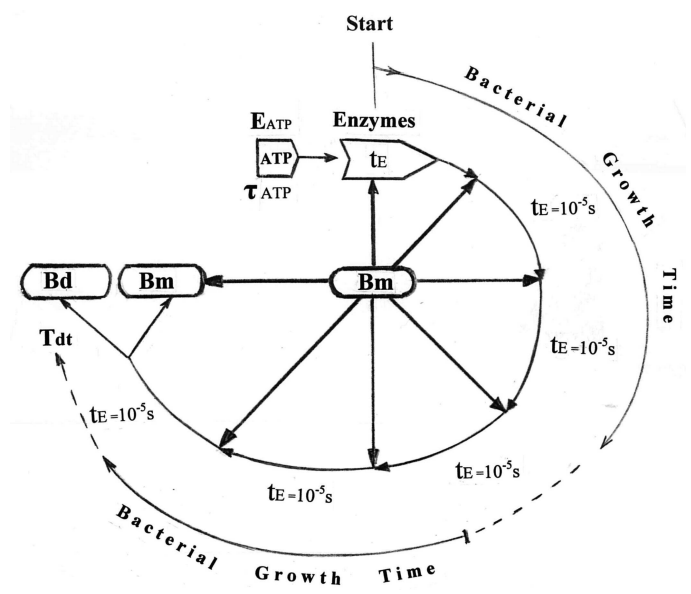

Fig. 3. A hypothetic model of bacterial clocks $\left(B_{m}\right.$-bacteriamother, $B_{d}$ - bacteria-daughter). Legend: The mean enzyme reaction-time $\left(t_{E} \approx 10^{-5} \mathrm{~s}\right)$ determines one clockwise moving. The ATP energy consumption $\left(E_{A T P}\right)$ from whole bacteria, per one enzyme reaction time $\left(t_{E}\right)$ determines the accuracy of bacterial clock. The doubling time of bacteria $\left(T_{d t}\right)$ determines the running Time $(T)$ of the clock

\section{Discussion}

In our case the calculated smallest time interval ' $\tau$ ' gives the accuracy of the bacterial clock, while the longest time $(T)$ gives the time for which a clock can remain accurate. In our hypothesis we accept that the time parameters of bacteria $\left(T_{d t}, T_{d t \text { min }}, T_{d t \max }, \mathrm{t}_{A T P}, \tau_{A T P}\right)$ are more random in comparison to the genetically determined bacterial mass and size. Because of that, we calculate the bacterial time-characteristics ( $T$ and $\tau$ ) as function of bacterial Mass $(M)$, size $(V / S)$ and Planck constant $(\hbar)$, accordingly to Wigner equations, taken as equalities. In our model we compare $\tau$ with time $\tau_{A T P}$ for which ATP energy goes to the enzyme molecules and $\mathrm{T}$ with doubling time $T_{d t}$ of bacterial cells, taken as maximum bacterial time-intervals. The received results have showed that the smallest time $\tau$ correspond to the real bacterial time-characteristics $\tau_{A T P}$ i.e., statistically $\tau_{A T P} \approx \tau_{\text {mean }}$. The individual bacterial values for $\tau$ satisfied the Wigner equation because of $\tau>\tau_{A T P}$ (Fig. 2). However, more than $70 \%$ of calculated values for $\tau$ were bigger than $\tau_{A T P}$. On the other hand the longest time $\mathrm{T}$ corresponds to real bacterial characteristics (doubling time $T_{d t}$ ) i.e., $T_{\text {mean }} \approx T_{d t \text { mean. }}$ Between the values of calculated longest time $T$ and experimental data of $T_{d t}$ exists a relatively good correlation (with $\mathrm{R}=0.47$ ). This is an additional argument in favor that the bacterial doubling time $T_{d t}$ represents the calculated longest time $T$. The individual calculated values for $T$ satisfied the Wigner equation because of $T<T_{d t \max }$ (Fig. 2). On the figures is observed that nearly $70 \%$ of T-values fall in a narrow window between $T_{d t \text { min }}$ and $T_{d t \text { max }}$ and the standard deviations of $T_{\text {mean }}$ and $T_{d t \text { mean }}$ differ slightly. The results for the longest time $\mathrm{T}$ are calculated by Equation $6\left(T_{V / S}=\right.$ $\left.M(V / S)^{2} / \hbar\right)$, using data for the bacterial volume to surface ratio. In all living cells the volume to surface ratio is smaller than the length of cells $(L)$. If we replace the volume to surface ratio with bacterial length (i.e., $\lambda=L$ ), the Equation 6 takes the form:

$T_{L}=M L^{2} / \hbar$

The calculated by Equation 10 values of $T_{L}$ will be considerably larger than calculated by Equation 6 values of $T$. For example, the mass of Mycoplasma mycoides is $1.55 \times 10^{-17} \mathrm{~kg}$, the length is $0.3 \mu \mathrm{m}$ and the doubling time is $3.6 \times 10^{3} \mathrm{~s}$. The calculated $T_{L}$ is $1.3 \times 10^{6}(\mathrm{~s})$ in comparison to the calculated by Equation 6 value of $T_{V / S}=3.69 \times 10^{2}(\mathrm{~s})$. In this case the equation from type of $T_{V / S} \approx T_{d t}<<T_{L}$ is valid. Thus, in this case the Wigner inequality will be valid and stronger. This example keeps the validity for all bacteria on Table 1 . By this fashion (using maximum length of bacterial cell, instead of their volume to surface ratio), the Wigner inequality could be valid more strictly. 
We can compare the received results and our model with those of other authors. For example, Zimmerman (1962) point out that a clock of accuracy about $1 \times 10^{-17}$ (s) and running time $1 \times 10^{-13}(\mathrm{~s})$ would have to weigh up to $1 \times 10^{7} \mathrm{D}$. For $1 \mathrm{D}=1.66 \times 10^{-27}(\mathrm{~kg})$ the mass of $10^{7}$ Daltons will be equals to $1.66 \times 10^{-20} \mathrm{~kg}$ (mass corresponding to the smallest bacterial mass $\sim 10^{-17} \mathrm{~kg}$ ). The calculated in our model mean value of clock accuracy $\tau_{\text {mean }}=6.65 \times 10^{-16}(\mathrm{~s})$ corresponds to the calculated by Pešić and Zimmerman accuracy, but the calculated in our model longest time ( $T$ and $T_{d t}$ data) differs drastically from Zimmerman's running time. The calculated mean running time $\left(T_{\text {mean }}\right)$ is close to the mean bacterial doubling time $\left(T_{d t \text { mean }}\right)$, but far away from the quantum area. As a compromise, it can be considered that the mean enzyme reaction-time $\left(t_{E} \sim 10^{-5} \mathrm{~s}\right)$ falls into the limit between the quantum and classical area of the physics, because this time can be presented as geometric mean between $\tau_{\text {mean }}$ and $T_{d t \text { mean }}$ by the ratio $t_{E} \sim\left(\tau_{\text {mean }} \times\right.$ $\left.T_{\text {mean }}\right)^{1 / 2}$. However, it just moves the bacterial clock one step ahead. Only the time of accuracy (in Pešić, Zimmerman and in our models) falls in the quantum area of physics, whereas the running Time $(T)$ falls in the classical area of physics. In conclusion, our calculations confirm the concept of Pešić (1993) that the living bacteria can be regarded as 'quantum clocks'. In previous publication the author (Atanasov, 2014) presents the problem whether bacteria can be regarded from quantum-mechanical point of view? The answer of this question is more positive than negative, because the basic physical parameters (mass-sizetime) of bacteria and the 'speed of bacterial growth' satisfied formally the Heisenberg inequalities.

\section{Conclusion}

In the study we confirmed the hypothesis of Pešić that the bacteria appear to be the smallest quantum clocks in the Nature.

\section{Ethics}

This article is original and contains unpublished material. The corresponding author confirms that it has no conflicts of interest.

\section{References}

Atanasov, A.T., 2012. Scaling of biological space and time: Volume to surface ratio in living organisms is proportional to lifespan. Trakia J. Sci., 10: 36-47.

Atanasov, A.T., 2005. The linear allometric relationship between total metabolic energy per lifespan and body mass of poikilothermic animals. Biosystems, 82: 137-142. DOI: 10.10.1016/j.biosystems2005.06.006
Atanasov, A.T., 2014. Scaling of volume to surface ratio and doubling time in growing unicellular organisms: Do cells appear quantum-mechanical systems? AIP Conf. Proc., 1618: 942-946. DOI: $10.1063 / 1.4897888$

Barrow, J.D., 1996. Wigner inequalities for a black hole. Phys. Rev. D, 54: 6563-6563. DOI: 10.1103/PhysRevD.54.6563

Boatman, E.S. and G.E. Kenny, 1970. Three dimensional morphology, ultrastructure and replication of Mycoplasma felis. J. Bacteriol., 101: 262-277.

Bock, E., 1976. Growth of Nitrobacter in the presence of organic matter. Archive Microbiol., 108: 305-312.

Brualla, L., 2013. Comment on 'The smallest clock'. Eur. J. Phys., 34: L65-L68. DOI: $10.1088 / 01143-0807 / 34 / 3 /$ L65

Davies, P.C.W., 2004. Does quantum mechanics play a non-trivial role in life? Biosystems, 78: 69-79.

Finster, K., Y. Tanimoto and F. Bak, 1992. Fermentation of methanethiol and dimethilsulfide by a newly isolated methanogenic bacterium. Archive Microbiol., 157: 425-430.

Furness, G. and M. de Maggio, 1972. Binucleate classical mycoplasmas pathogenic for goats. Infection Immunity, 5: 433-441.

Gouin, E., H. Gantelet, C. Egile, I. Lasa and H. Ohayon et al., 1999. A comparative study of the actin-based motilities of the pathogenic bacteria Listeria monocytogenes, Shigella flexneri and Rickettsia conorii. J. Cell Sci., 112: 1697-1708.

Goel, A., 2008. Molecular Evolution: A Role for Quantum mechanics in the Dynamics of Molecular Machines that Read and Write DNA. Quantum Aspects of Life, 97 (books.google.com)

Gusev, M.B. and L.A. Mineeva, 1985. Microbiology. 2nd Univ. Ed., Moscow (in Russian).

Hillebrand, H., C.D. Dürselen, D. Kirschtel, U. Pollingher and T. Zonary, 1999. Biovolume calculation for pelagic and benthic microalgae. J. Phycol., 35: 403-424.

Higgins, M.L., J. Coyette and G.D. Shockman, 1973. Sites of cellular autolysis in Lactobacillus acidophilus. J. Bacteriol., 116: 1375-1382.

La Riviere, J.W.M. and K. Schmidt, 2006. Morphologically conspicuous sulfur-oxidizing eubacteria. Prokaryotes, 7: 941-954.

Minkov, I.M., 1991. Cellular Bioenergetics. 'Kliment Ochridski' University Ed., Sofia, Bulgaria.

Metzler, D.E., 1977. Biochemistry (The chemical reactions of living cells). Iowa State University. Academic Press. New York, San Francisco, London.

Mohseni, M., Y. Omar, G.S. Engel and M.B. Plenio2014. Quantum Effects in Biology. 1st Edn., Cambridge University Press, Cambridge, ISBN-10: 1139952218.

Pešić, P.D., 1993. The smallest clock. Eur. J. Phys. 14: 90-92. DOI: 10.1088/0143-0807/34.3 
Razin, S. and B.J. Cosenza, 1966. Growth phases of Mycoplasma in liquid media observed with phasecontrast microscope. J. Bacteriol., 91: 858-869.

Salser, W., J. Janin and C. Levinthal, 1968. Measurement of the unstable RNA in exponentially growing cultures of Bacillus subtilis and Escherichia coli. J. Molecular Biol., 31: 237-266.

Salecker, H. and E.P. Wigner, 1958. Quantum limitations of the measurement of space-time distance. Physical Rev., 109: 571-577.

Stemler, M.E., G.W. Stemke and J.A. Robertson, 1987. ATP measurements obtained by luminometry provide rapid astimation of Ureaplasma urealyticum growth. J. Clin. Microbiol., 25: 427-429.

Schlegel, H.G., 1985. Allgemeine Mikrobiologie. 1st Edn., Georg Thieme Verlag, Stuttgart, New York.
Sun, J. and D.Y. Liu, 2003. Geometric model for calculating cell biovolume and surface area for phytoplankton. J. Plankton Res., 25 :1331-1346.

Starr, M.P. and J.M. Schmidt, 1981. Prokaryotes Diversity, p.3-42. In: M.P. Starr, Stolp H., Truper

Zimmerman, E.J., 1962. The macroscopic nature of space-time. Am. J. Physics, 30: 97-105. DOI: $10.1016 / \mathrm{j} /$ biosystems2005.06.006

Wigner, E.P., 1957. Relativistic invariance and quantum phenomena. Rev. Modern Physics, 29: 255-268. DOI: 10.1103/RevModPhys/29.255

Wigner, E.P., 1972. On the Time-Energy Uncertainty Relation. In: Aspects of Quantum Theory. Salam, A. and E.P. Wigner, (Eds.), Cambridge University Press, Cambridge.

Waites, K.B. and D.F. Talkington, 2004. Mycoplasma pneumoniae and its role as a human pathogen. Clin. Microbial. Rev., 17: 697-728. 